From all central nervous system tumors, gliomas are the most common. Nowadays, researchers are looking for more efficient treatments for these tumors, as well as ways for early diagnosis. Receptor tyrosine kinases (RTKs) are major targets for oncology and the development of small-molecule RTK inhibitors has been proven successful in cancer treatment. Mutations or aberrant activation of the RTKs and their intracellular signaling pathways are linked to several malignant diseases, including glioblastoma. The progress in the understanding of malignant glioma evolution has led to RTK targeted therapies with high capacity to improve the therapeutic response while reducing toxicity. In this review, we present the most important RTKs (i.e. EGFR, IGFR, PDGFR and VEGFR) currently used for developing cancer therapeutics together with the potential of RTK-related drugs in glioblastoma treatment. Also, we focus on some therapeutic agents that are currently at different stages of research or even in clinical phases and proved to be suitable as re-purposing candidates for glioblastoma treatment.

Key words: glioma, RTKs, targeted therapy.

Contemp Oncol (Pozn) 2020; 24 (1): 55-66 DOI: https://doi.org/10.5114/wo.2020.94726

\section{Receptor tyrosine kinase targeting in glioblastoma: performance, limitations and future approaches}

\author{
Oana Alexandru ${ }^{1^{*}}$, Cristina Horescu ${ }^{2^{*}}$, Ani-Simona Sevastre ${ }^{3^{*}}$, \\ Catalina Elena $\mathrm{Cioc}^{2}$, Carina Baloi ${ }^{2}$, Alexandru Oprita ${ }^{2}$, Anica Dricu ${ }^{2}$
}

\begin{abstract}
${ }^{1}$ Department of Neurology, University of Medicine and Pharmacy of Craiova and Clinical Hospital of Neuropsychiatry Craiova, Craiova, Romania

${ }^{2}$ Unit of Biochemistry, University of Medicine and Pharmacy of Craiova, Craiova,

Romania

${ }^{3}$ Unit of Pharmaceutical Technology, University of Medicine and Pharmacy of Craiova, Craiova, Romania
\end{abstract}

* These authors contributed equally to this work.

\section{Introduction}

Gliomas are a group of brain tumors originating from the glial cells (either astrocytic or oligodendroglial). Their classification is based on cell biology, histology and clinical evolution. Although the current classification of brain tumors includes genetic and epigenetic abnormalities and clinico-pathological features, clinicians are still using the historical classification to define the tumor entities. Until recently, gliomas were divided into low-grade gliomas (LGGs) (grade I-II) and high-grade gliomas (HGGs) (grade III and IV), according to the 2007 report of the WHO classification [1]. The WHO presented in 2016 a major restructuring of the embryonal central nervous system tumors, by incorporating new entities defined both by molecular and histological features, including IDH-wildtype glioblastoma, IDH-mutant glioblastoma; H3 K27M-mutant diffuse midline glioma; RELA fusion-positive ependymoma; WNT- and SHH-activated medulloblastoma; and C19MC-altered multilayered rosettes embryonal tumor [2]. There are several studies showing that the molecular background of the discussed entity is very complex $[3,4]$. Basically, because of the discrepancies in the clinical evolution of tumors with different molecular background, this classification is a problematic issue. HGGs are the most aggressive brain tumors among gliomas. The median survival of patients diagnosed with HGGs is only 14.6 months [5]. HGGs include anaplastic astrocytoma (AA), anaplastic oligodendroglioma (AO) and glioblastoma (GB). The origin of these tumors is in the supporting neuroglial cells of the central nervous system. The most aggressive of these primary brain tumors are GB. It is obvious that GB individuals require special attention and care, mainly because all HGGs can be debilitating, causing physical and cognitive impairment, epileptic seizures, depression and personality changes. In the last years, specialists have focused their energy on providing new therapies for these patients, in order to improve their lifestyle and survival. In spite of the efforts made until now, the standard of care of newly diagnosed GB remains surgery (maximal safe resection) followed by radiotherapy and adjuvant chemotherapy [6-8]. The adjuvant temozolomide associated with radiotherapy has improved the median survival, which was only 12.1 months. However, several problems linked to resistance towards chemotherapy or radiotherapy need to be solved. Microenvironment, cellular morphology and genetic characteristics are a few of the aspects to which cancer cells can adapt in order to survive, leading to drug resistance [9]. In the light of these data, it is obvious that the decisions regarding the treatment must be taken on an individual basis. 
In recent years, specialists focused on targeted molecular therapies. Known to be involved in cancer development and therapy, receptor tyrosine kinases (RTKs) are of particular importance [10-13].

New chemotherapeutic strategies in GB treatment are frequently proposed, but drug development and registration are consuming increased financial resources and time. Therefore, drug re-purposing represents a new pipeline for the pharmaceutical industry to find new uses in oncology for already existing non-cancer drugs. In this review we focused on some therapeutic agents that are at different stages of research or in clinical phases endowed with the potential to become re-purposing candidates for GB treatment.

\section{Receptor tyrosine kinases}

The molecular structure of RTKs includes a ligand-binding region in the extracellular domain, a single trans-membrane helix, and a cytoplasmic region. The cytoplasmic region includes the protein tyrosine kinase (TK) domain and the additional carboxy terminal and juxtamembrane regulatory regions. In the human proteome there are 58 currently known RTKs divided into 20 families [14]. RTKs are involved in regulating proliferation, differentiation, cell survival, metabolism, cell migration, and cell cycle control [15]. In 1990, Ulrich and Schlessinger demonstrated that the activation of RTKs by growth factor binding results in the dimerization and/or oligomerization of the receptor [16]. Actually, the dimerization can be ligand- or receptor- mediated, or both receptor- and ligand-mediated [17]. The dimerization of the extracellular regions of RTKs leads to activation of the intracellular tyrosine kinase domain. These changes lead to the release of the cis-autoinhibition while the trans-autophosphorylation is enabled and the tyrosine kinase domain becomes active [18]. Also, the autophosphorylation of RTKs results in the recruitment of downstream signaling proteins which contain Src homology-2 or phosphotyrosine-binding domains. By binding these domains to specific phosphotyrosine residues, the cellular signaling pathway is activated [19]

Another response to the activation of RTKS is the down-regulation of the receptor. The result of this process is the degradation of the ligand and of the receptor [20]. Also, it is known that there is a connection between the function of protein kinases and ubiquitylation, which is very important in some critical events involved in cell signaling such as regulation of protein degradation, processing and cellular trafficking [21]. The mutations or aberrant activation of the intracellular signaling pathways of RTKs are linked to a series of diseases including cancer, arteriosclerosis, diabetes, and angiogenesis. Therefore, in recent years serious efforts were made to develop molecular targeting drugs able to fight the RTK aberrations. The most studied molecular targets are epidermal growth factor receptor (EGFR), insulin growth factor receptor (IGFR), vascular endothelial growth factor receptor (VEGFR), platelet-derived growth factor receptor (PDGFR) and fibroblast growth factor receptor (FGFR) [22, 23].

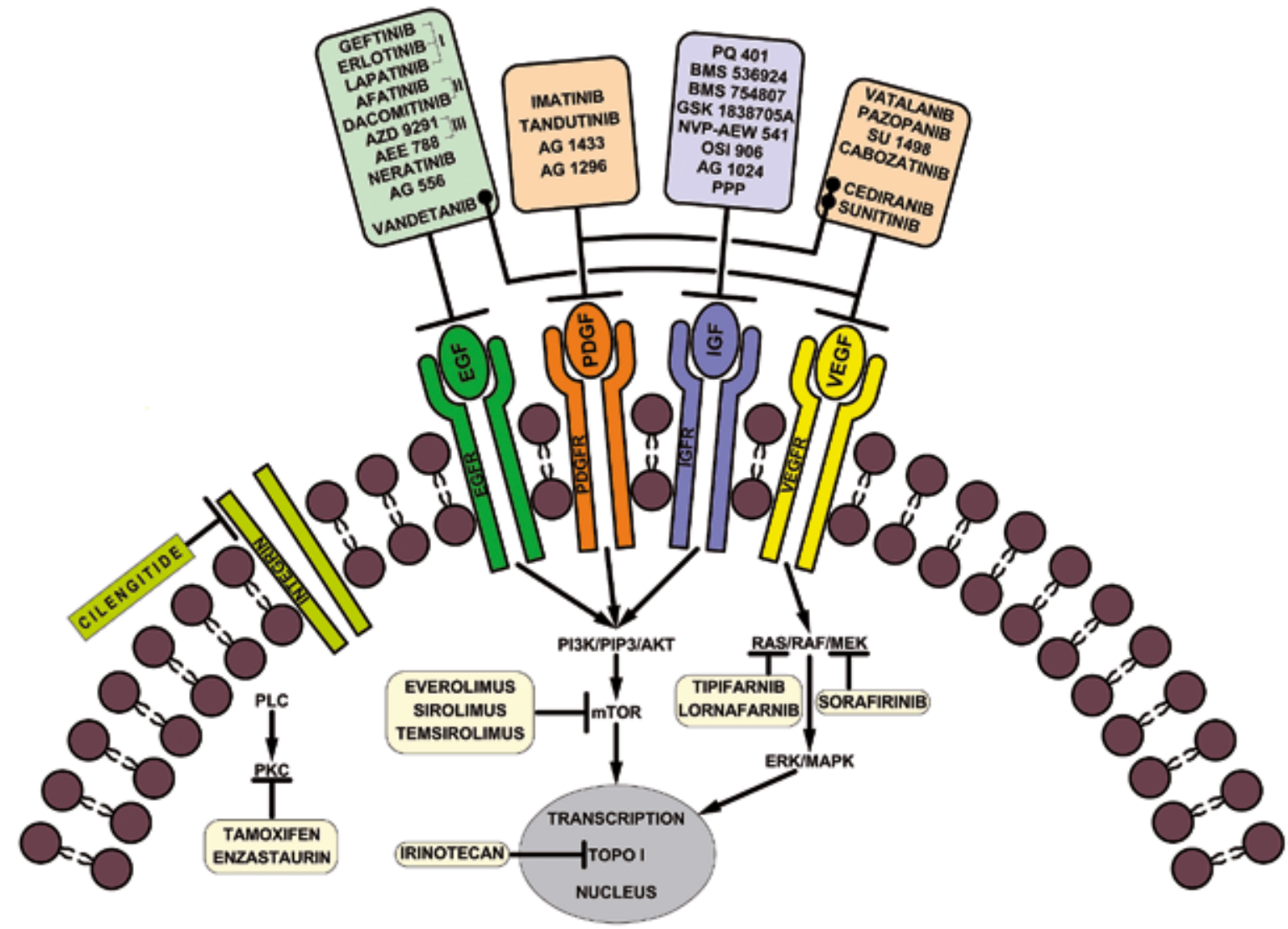

Fig. 1. Inhibitors used in glioblastoma therapy 


\section{Receptor tyrosine kinase inhibitors for glioblastoma treatment}

In accordance with the National Cancer Institute (NCI) and the US Food and Drug Administration (FDA), targeted therapies are a set of drugs capable of blocking molecular targets involved in growth, spread and tumor progression [24]. Being designed to interact only with the molecular target, such therapies spare the normal cells. Also, being able to inhibit tumor cell proliferation, they are cytotoxic. Therefore, they can be considered instruments of precision medicine. Small molecule therapies against RTKs are among these targeted therapies. Currently, some of them are used in preclinical studies, while others have already been approved for clinical trials or for clinical use in tumor treatment including HGGs, as mentioned in Figure 1.

The most relevant RTK inhibitory drugs used in cancer therapy are briefly presented in Table 1.

Because EGFR is overexpressed in about $60 \%$ of GBs, small molecule EGFR inhibitors were developed [25]. Among the first small molecule inhibitors against EGFR preclinically tested are gefitinib (Iressa; ZD1839), erlo- tinib (Tarceva; OSI-774), and lapatinib (Tykerb/Tyverb; GW572016). These inhibitors showed promising results in preclinical studies $[26,27]$. However, the results were rather mixed in clinical trials. Gefitinib alone or in association with radiotherapy proved to have only a minimal response in patients diagnosed with GBs, although the drug was well tolerated [28, 29]. However, in 2005, Franceschi et al. proved in a phase II study of the Grupo Italiano Cooperativo di Neuro-Oncologia (GICNO) that the drug could be more efficient as a second line treatment for patients with HGGs [30]. In recent years, clinical studies proved to have similar results [31].

Similar results were obtained with erlotinib [32, 33]. Even in more recent years the drug showed only minimal benefits [34]. Lapatanib, another first generation EGFR inhibitor, also had only limited results in clinical trials either alone or in combination with temozolomide $[35,36]$. Because of these rather poor results, a second generation of EGFR inhibitors was designed to inhibit the EGFR. Among them, afatinib and dacomitinib were approved by the FDA. In 2015, a phase I/phase II study regarding afa-

Table 1. Small molecule receptor tyrosine kinase inhibitors used in cancer therapy

\begin{tabular}{|c|c|c|}
\hline Target & Molecules & Observations \\
\hline \multirow[t]{4}{*}{ EGFR } & $\begin{array}{l}1^{\text {st }} \text { generation inhibitors: } \\
\text { Gefitinib } \\
\text { Erlotinib } \\
\text { Lapatanib }\end{array}$ & $\begin{array}{l}\text { They showed promising results in preclinical studies, but with mixed results in clinical trials } \\
\qquad[22-25]\end{array}$ \\
\hline & $\begin{array}{c}2^{\text {nd }} \text { generation inhibitors: } \\
\text { Afatinib } \\
\text { Dacomitinib }\end{array}$ & $\begin{array}{l}\text { Both drugs were approved by the FDA } \\
\text { Afatinib had limited activity in combination with temozolomide [33] }\end{array}$ \\
\hline & $\begin{array}{c}3^{\text {rd }} \text { generation inhibitors: } \\
\text { AZD } 9291 \\
\text { AEE } 788\end{array}$ & $\begin{array}{l}\text { AZD } 9291 \text { proved to have better activity and selectivity than the previous inhibitors } \\
\text { The third-generation EGFR inhibitor AZD9291 overcomes primary resistance by continuously } \\
\text { blocking ERK signaling in glioblastoma [36] } \\
\text { AEE } 788 \text { also inhibits VEGFR [38] }\end{array}$ \\
\hline & $\begin{array}{l}\text { Others: } \\
\text { Vandetanib } \\
\text { Neratinib } \\
\text { AG556 }\end{array}$ & $\begin{array}{l}\qquad \text { Vandetanib also inhibits VEGFR [39] } \\
\text { AG556 had promising results when used in combination with radiotherapy [43] }\end{array}$ \\
\hline PDGFR & $\begin{array}{l}\text { Imatinib mesylate } \\
\text { Tandutinib } \\
\text { AG } 1433 \\
\text { AG } 1296\end{array}$ & $\begin{array}{l}\text { Imatinib showed no significant changes in the HGGs and especially GBM tumor growth [46] } \\
\text { Better results were obtained in combination with hydroxyurea [47] } \\
\text { Tandutinib had little effect [49] } \\
\text { AG } 1433 \text { and AG } 1296 \text { used alone are rather effective }[50,51]\end{array}$ \\
\hline IGF-R & $\begin{array}{l}\text { PQ } 401 \\
\text { Picropodophyllin } \\
\text { BMS } 536924 \\
\text { BMS } 754807 \\
\text { NVP-AEW } 541 \\
\text { OSI } 906 \\
\text { AG } 1024\end{array}$ & $\begin{array}{l}\text { PQ 401, BMS } 536924 \text { and picropodophyllin suppressed the growth and migration of GBM cells } \\
\text { GSK } 1838705 \text { A and NVP-AEW541 induced apoptosis [63-67] } \\
\text { OSI } 906 \text { and BMS } 754807 \text { had good results in vitro } \\
\text { AG1024 had rather modest inhibition activity alone or in combination with radiotherapy [68] }\end{array}$ \\
\hline VEGFR & $\begin{array}{l}\text { Vatalanib } \\
\text { Pazopanib } \\
\text { Sunitinib } \\
\text { Cediranib } \\
\text { Thalidomide } \\
\text { Cabozantinib } \\
\text { SU } 1498\end{array}$ & $\begin{array}{c}\text { Vatalanib enhances the antiangiogenic activity [54] } \\
\text { Disappointing results were obtained for pazopanib in combination with lapatinib [57] } \\
\text { No promising activity for GBM patients treated with sunitinib [58] } \\
\text { Cediranib is an inhibitor of VEGFR, PDGFR, and c-kit [59] } \\
\text { Thalidomide had a good effect as palliative drug in advanced secondary glioblastoma [60] } \\
\text { Cabozantinib had good results both in vitro and in clinical trials [61, 62] } \\
\text { SU1498 had a limited anti-tumor activity [51] }\end{array}$ \\
\hline
\end{tabular}


tinib alone or in combination with temozolomide proved that the drug was safe but with limited activity [37]. Also, single-agent dacomitinib proved to have limited activity in a phase II clinical trial in recurrent glioblastoma patients with EGFR amplification [38], following preclinical studies with good results [39]. The third generation of EGFR inhibitors is nowadays being tested pre-clinically, but also in clinical trials. AZD9291 demonstrated to be efficient both in vitro and in vivo GB models. This drug has better activity and selectivity than the previous inhibitors. The drug has a better capacity to inhibit proliferation and prolongs the survival of GB cells [40]. Since 2018, the drug is being tested in a phase I/phase II clinical trial [41]. Another EGFR/Erb inhibitor is AEE788. The drug also inhibits VEGFR. It was tested in a phase I clinical trial developed for patients diagnosed with recurrent $\mathrm{GB}$. The results were disappointing due to the toxicity and minimal activity of the inhibitor [42]. Neratinib is another inhibitor of EGFRs investigated in clinical trials for GB patients [43].

In the last years, we also investigated a number of small molecule EGFR inhibitors as potential targeted therapy on HGG cell lines. In 2018 we investigated the effect of tyrphostin AG556 (an EGFR inhibitor) on 11 and 15 HGG cells. Currently used as monotherapy, the inhibitor had only modest results. However, when combined with radiotherapy, the inhibitor induced radiosensitivity in 11 HGG cells [44]. This proved once again that HGG cells are able to develop resistance to therapies. The capacity of these cells to synthesize constitutive active receptors makes the targeted therapies ineffective.

PDGFR is another family of receptor tyrosine kinases that is overexpressed in HGGs, especially in GBs [45]. PDGFRA is amplified in about $15 \%$ of GBs [46]. This explains the efforts made to discover and test new small molecule inhibitors to target this receptor. Currently, many inhibitors are undergoing in vitro and in vivo preclinical tests and some of them are already approved for clinical trials. Imatinib mesylate (Gleevec/ST1571) is a small molecule inhibitor which has inhibitory effects on PDGFR. Although the inhibitor proved to have good effects for other malignancies, in the case of HGGs and especially GBs, imatinib mesylate showed no significant changes in the tumor growth. The drug failed the clinical trials and the patient survival remained unchanged [47]. Because of these facts, the inhibitor was next tested in combination with hydroxyurea, another classical chemotherapeutic drug. The clinical trial concluded that the combination had no benefit when compared to the single treatment with hydroxyurea [48]. In the last years, in vitro studies on GB cells proved that imatinib mesylate increases the migration and invasion of $G B$ cells, a fact that explains the anterior failures of the drug [49]. Tandutinib, a PDGFRB inhibitor, was also tested in clinical trials in patients with recurrent GB. The drug had little effect [50]. Even since 2008 we have been interested to test the effect of AG1433, which is also an in vitro PDGFR inhibitor in several HGG cell lines $(8,18$, and 38). The results were promising [51].

In 2015 we also tested the effect of the same inhibitor, AG1433, on GB9B cells in vitro. The cytotoxic effect of the drug was rather modest [52]. In the same period, another tyrphostin, AG-1296, had good effects on GB cells both in vitro and in vivo [53].

In 2019, we reported the effect of AG1433 alone and in combination with radiotherapy on 11 and 15 HGG cell lines. We found that although the use of the inhibitor alone was rather effective, the association with radiation therapy was not more effective when compared with the single treatment [54].

VEGFR is another target for glioblastoma patients. Vatalanib (PTK787) is an inhibitor of VEGFR2, PDGFR and c-kit which had little effect on GB patients alone or in combination with other chemotherapeutics or radiotherapy. However, the drug seemed to enhance the antiangiogenic activity [55]. Sorafenib is another small molecule inhibitor of VEGFR with a small effect on GB when used in combination with temsirolimus. It is in a phase II clinical study [56]. Tivozanib is a small molecule inhibitor of angiogenesis with good anti-angiogenic effects on GB. However, the drug was not able to change the volume of the tumors [57]. Pazopanib was also tested in clinical trials in combinations with lapatinib. The results were rather disappointing [58] In 2013, Batchelor et al. reported that cediranib, a small molecule inhibitor of VEGFR, PDGFR, and c-kit, showed a small effect on the neurological status of the patients but did not improve the progression of the disease or the survival of the GB patients [59]. Another antiangiogenic agent which proved good effects on GB patients is thalidomide. The drug had a good effect when used as a palliative drug for patients with advanced secondary GB [60]. SU1498 is a VEGFR inhibitor that proved to have a cytotoxic effect on GB9B cells. However, its antitumor activity was rather limited [52].

YKL-40, a mesenchymal marker known as human cartilage glycoprotein-39 or chitinase-like protein 1, seems to have a key role in the motility and migrating features of glioma stem like cells and in their differentiation into endothelial cells, involved in angiogenesis [61]. It was proven that YKL-40 upregulates VEGF expression, and tumor vasculogenesis induced by YKL-40 is partially dependent on VEGF [62]; therefore therapies targeting YKL-40 may have potential benefit in GB treatment.

IGF-1R is another receptor tyrosine kinase that proved to be an interesting target for GB treatment. In the last years, a number of small molecule inhibitors against IGF-1R have been tested on GB cells in vitro and in vivo. Among them, PQ401, BMS-536924 or PPP (picropodophyllin/AXL1717) proved to be able to suppress the growth and migration of GB cells, while GSK1838705A or NVP-AEW541 induced apoptosis either alone or in association with other chemotherapeutic drugs [63-67]. Also, inhibitors such as OSI-906 and BMS-754807 proved good results in vitro on GB cells [68]. Our group studied since 2007 the capability of tyrphostin AG1024 to inhibit IGFR on a series of HGG cells lines. First we studied the 18 and 38 HGG cell lines [69]. In the next year, we added some other HGG cell lines: MO59J, MO59K, and 8. The activity of the inhibitor was rather modest. Similar results were obtained when combining the inhibitor with ionizing radiation [51].

Somatic mutations of FGFR are rare in GB, but there are studies suggesting that modifying FGFR signaling 
influences glioblastoma progression and patient survival [70]. Small molecules which inhibit the FGFR tyrosine kinases are currently being studied, emphasizing the therapeutic potential of this signaling pathway [71]. Some small-molecule inhibitors such as lenvatinib, ponatinib, dovitinib and brivanib, also target other RTKs, while others are FGFR selective, such as PD173074, BGJ398, AZ4547, and JNJ-493 [72].

In a recent study, a large-scale shRNA screen was used to identify FGFR signaling as a target in pediatric glioma, proving that dovitinib, ponatinib, AZ4547, and PD173074 better reduce the growth of glioma cells in vitro than temozolomide [73].

In December 2019, a trial involving BGJ398 in patients with recurrent glioblastoma was completed, but so far, no results have been published [74].

A phase I/II trial involving TAS-120 is currently recruiting patients with advanced solid tumors, with and without FGF/FGFR-related abnormalities [75].

Rapamycin (sirolimus) has been identified to inhibit the mTOR and, specially, the mTORC1 complex [76]. Rapamycin derivatives (temsirolimus, everolimus and ridaforolimus), also named rapalogues, have been synthesized. At present, they are gaining considerable interest. By using clinicaltrials.gov lists regarding sirolimus/everolimus/temsirolimus treatment in GB patients, we found that 7 clinical trials were recruiting in 2019 [77].

The multitargeted approaches may represent a method for effective selection of resistant tumor subclones. Vandetanib is a multitargeted tyrosine kinase inhibitor (VEGFR, EGFR) that was studied in clinical trials. The drug was well enough tolerated but the antitumor effects were limited [78]. In 2015 another phase I clinical study determined that the co- administration of vandetanib in association with sirolimus is safe for patients with recurrent GB [79]. Also, in another clinical trial vandetanib proved to be safe in association with standard chemotherapy in newly diagnosed GB patients [80]. Two other multitarget small molecule inhibitors which target VEGFR and other receptors are XL184 (cabozantinib) and PD173074. Cabozantinib had good results both in vitro and in clinical trials, and PD173074 had good results in vitro $[81,82]$. Sunitinib is a multiple kinase inhibitor of VEGFR, PDGFR, FLT1, FLT1/KDR, FLT3, and RET kinases with no promising activity for GB patients [83].

In conclusion, targeted therapy against receptor tyrosine kinases represents a hope for GB patients. However, the efforts made by specialists should also be focused on fighting against resistance to therapy, to discover drugs able to pass the blood brain barrier, to use multi-targeted therapies, but also to discover and use biomarkers that can predict the outcome of therapies.

\section{Antibody therapies targeting the RTKs' extracellular domain}

Apart from the kinase domain, the extracellular domain of RTKs may represent a viable target by using antibody therapies as antagonists. Because of their large size, they do not freely cross the blood-brain barrier (BBB); therefore engineered antibodies (such as directed antibodies with transferrin receptor optimized binding) must be used to enable them to access the GB tumors. Also, to bypass the $\mathrm{BBB}$, alternative antibodies can be delivered inside the brain using Ommaya reservoirs [22].

Cetuximab is a monoclonal EGFR targeting antibody used for GB treatment. It prevents RTK activation by targeting the extracellular domain of EGFR [84]. Its activity was minimal in phase $1 /$ clinical trials on recurrent $G B$ patients [85]. Also, onartuzumab was used to inhibit the tumor growth of orthotopic U87 GBM xenograft [86]. Dalotuzumab (MK-0646 or H7C10/F50035) is a humanized monoclonal IGF-1R antibody shown to induce apoptosis and to reduce cell proliferation [87].

\section{RTK drug resistance in glioblastoma patients}

The resistance to RTK drugs has many causes. Usually, monotherapies yield minor results, mostly because of the functionally redundant pathways. Due to the fact that intracellular signal redundancy is the main cause of therapeutic failure by using a single inhibitor, concurrent blocking of multiple receptors or of an RTK inhibitor together with radio-, chemo or immunotherapy is an applicable strategy. Recent preclinical and clinical studies suggest the need for concomitant inhibition of multiple RTKs or for inhibition of their common downstream signaling. Hence, there has been a growing interest in testing the inhibitors of PI3K, AKT and the TORC1/2 complexes. A multitarget treatment may be a good solution when certain subclones of the tumor become resistant to single treatment by creating mutations; therefore an option to overcome resistance is to act selectively on these mutations.

There are two types of approaches mentioned in the literature: the vertical inhibition approach in which the molecular targets are part of the same cellular signaling axis, and the horizontal inhibition approach where the multitarget ligand is involved in distinguished nodes of different pathways [88]. These approaches are achieved by using co-administration of drugs (Akt/mTOR, MDM2/ mTOR, PI3K/CDK inhibitors) or by using multi-target ligands (PDK1/Aurora A, PDK1/CHK1, Akt/p70S6K, EGFR/ PKC inhibitors) [89]. For example, a study performed by Graves-Deal et al. showed that the multi-RTK inhibition strategy managed to overcome both de novo and acquired resistance to EGFR therapies. The efficiency of multiple EGFR-targeted antibodies (panitumumab, cetuximab, and MM-151) could be enhanced by adding small molecule RTK inhibitors (crizotinib, cabozantinib, and BMS-777607). Also, by adding crizotinib, resistance to cetuximab in nude mice xenografts was overcome [90]. This strategy could also be applied for GB treatment. Wei et al. performed a study on patient-derived glioblastoma xenografts grown in mice. The results showed that copy number variations and mutations did not correlate with drug resistance, but increased heterogeneity and activation of the ERK and SRC kinases in drug-resistant tumors. The tumor growth was prevented by combining the different pathway inhibitors ( $m$ TOR, ERK, SRC) in mTOR inhibitor-resistant GB mice. The rewiring events were detected a few days after the beginning of the treatment, at the single-cell level [91]. 
Another option to overcome the RTK inhibitors resistance is to use blockers for the apoptosis inhibitors. In a study performed by Ziegler et al., in vitro inhibition of PDGFR in human GB cells started the apoptosis intrinsic pathway, but caspase activation could be blocked by inhibiting the apoptosis proteins. Therefore, concomitant inhibition of apoptosis proteins may overcome the resistance to RTK inhibitors, improving treatment outcomes [92].

In conclusion, the concurrent inhibition of different cellular pathways is a new promising strategy that is attempting to overcome the onset of chemoresistance. These strategies may involve the combination of multiple selective inhibitors blocking different targets in the same pathway, the concurrent blockade of key proteins of the signaling pathways, or the multidirectional inhibition of specific oncoproteins. All these approaches represent a valid strategy in GBM therapy, especially when the patient genetic pattern is the target.

\section{Repurposed drugs with potential use in glioblastoma therapy}

There are many innovative chemotherapeutic strategies developed in GB treatment, but nowadays regulations concerning drug development and registration require a long time and increased financial resources. The pharmaceutical industry is trying various other pathways in order to put drugs faster on the market. Besides that, it is known that physicians may prescribe "off-label" drugs, though this represents a controversial practice in some fields (pediatrics, oncology) [93]. One strategy applied is drug repositioning, also known as drug re-purposing. It is a pharmaceutical strategy applied in oncology and other areas based on finding new indications for already approved drugs, in order to treat off-label diseases [94].

The reason for using drug re-purposing is due to the ability of small molecule agents to target distinct cellular proteins. Thus, the same molecule can be used to target multiple pathways involved in malignant diseases that are usually considered to be unrelated (polypharmacology) [95].

Because it skips many phases [96], as can be seen in Figure 2, this strategy has many advantages.

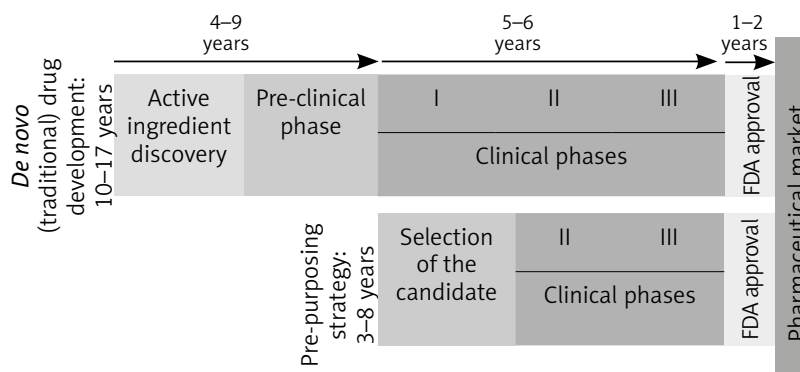

Fig. 2. De novo and re-purposing drug development phases. Unlike the drugs that follow the conventional pathway to the pharmaceutical market, re-purposing candidates shorten the time needed to market by omitting some initial steps, which go directly into the clinical study phases (FDA - Food and Drug Administration. I, II, III stages in the clinical development [clinical phases])
The molecules already in use have well-known pharmacological data, a fact that shortens the period for approval, but also the final price. Furthermore, most of these drugs are generics, so their cost of production is lower than for the patented drugs [97].

However, key obstacles must be mentioned such as registration, reimbursement and implementation of the re-purposed drugs. For example, in Europe only the holder of the marketing authorization can apply for the extension of a marketing authorization [98]. Also, non-commercial organizations usually lack resources required to finish and maintain the marketing authorization. There is still a doubt regarding the necessity of large randomized controlled trials to confirm the efficiency of a re-purposed agent and the use of the authorization dossiers' safety data, in order to overleap phase I studies [99].

For example, out of 44 off-label recommendations listed in the NCCN Clinical Practice Guidelines in Oncology (NCCN Guidelines), only 14 were approved by the FDA and/ or are subjects of randomized controlled trials [100].

Concerning central nervous system (CNS) therapy, only the FDA approved agents with ability to cross the blood brain barrier (BBB) may become re-purposing candidates [95]. By using the PubMed database published between 2010 and 2019 and the site clinicaltrials.gov, we gathered a list of agents that have re-purposing potential for GB treatment. In this short review, we indicated the various approaches used to repurpose drugs in GB therapy and we also highlighted their limitations.

Some of the mechanisms involved in GB therapy were completely elucidated, but many still remain unclear. In Figure 3, we illustrated the plethora of drugs with repurposing potential in GB therapy, but the number of studies in this field is significantly higher [94, 101-126].

In this review, we focused on the following drugs that were tested as re-purposing candidates: CNS drugs (chlorpromazine, pimozide, fananserin, trifluoperazine, thioridazine, imipramine, valproate, propentofylline), antimalarial drugs (chloroquine, mefloquine), antidiabetics (metformin), disulfiram, lonidamine, rapamycin, temsirolimus, everolimus and ridaforolimus.

Several studies investigated the properties of some FDA-approved psychotropic molecules to inhibit the proliferation and migration of GB cells $[109,127]$.

For example, chlorpromazine is a specific and potent inhibitor of the kinesin KSP/Eg5 leading to mitotic arrest and defective, monopolar spindles [128]. It is also involved in autophagic cell death due to inhibition of the AKT/mTOR signal transduction axis in human glioma cells [129]. Antipsychotic drugs such as chlorpromazine and pimozide were tested on glioblastoma cells and they showed tumor suppressing ability [130].

Fananserin, a dopamine receptor D4 (DRD4) inhibitor, selectively induced autophagy in GB stem cells [131].

Trifluoperazine, a dopamine receptor D2 antagonist, inhibits both growth and proliferation of GB cells in a dose-dependent manner [132].

A recent study showed that thioridazine inhibits autophagy and sensitizes glioblastoma cells to temozolomide, 


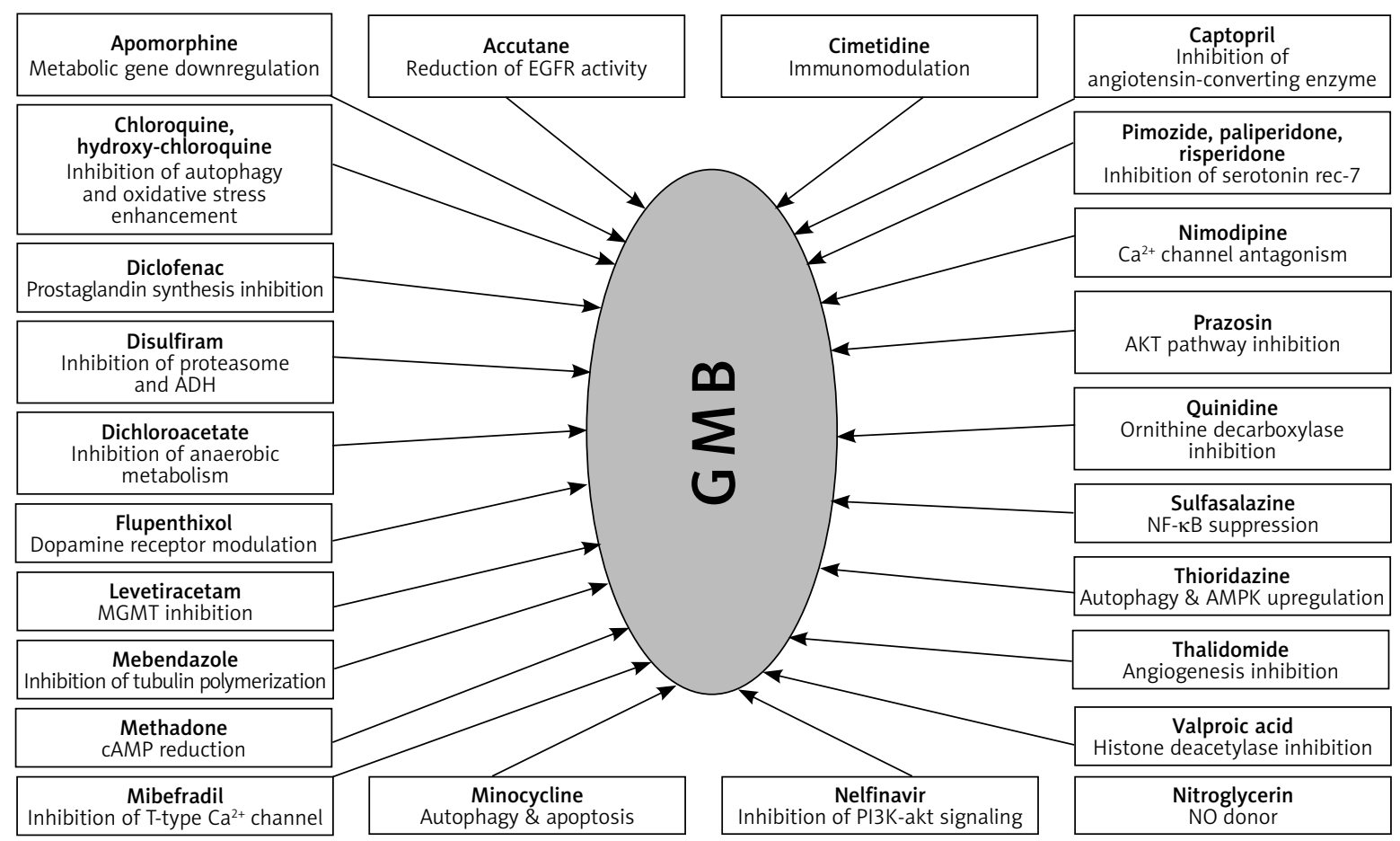

EGFR - epidermal growth factor receptor, AKT - protein kinase B, MGMT-O(6)-methylguanine-DNA-methyltransferase, NF-к $\beta$ - nuclear factor $\kappa \beta$, cAMP-cyclic adenosine monophosphate, AMPK - adenosine monophosphate-activated protein kinase, $\mathrm{Ca}^{2+}$ - calcium, $\mathrm{NO}$ - nitric oxiderirad

Fig. 3. Drugs with re-purposing potential in glioblastoma therapy

inhibiting tumor growth in vivo and increasing survival in tumor-bearing animals [133].

It has been recently observed that antidepressants, especially imipramine and amitriptyline, can downregulate the "stemness genes" Sox1, Sox2, Ki67, Nestin, and CD44 after tricyclic antidepressant treatment. They also hypothesized that these compounds can affect tumor plasticity and immunity by influencing immune cells, reactive oxygen species and pro/anti-inflammatory cytokines [134].

Valproic acid is an anti-epileptic agent which acts by blocking sodium channels, GABA transaminase, and calcium channels [135]. Valproate is prescribed in epilepsy, migraines and acute manic episodes [136]. It was shown to have anticancer effect in glioblastoma, by reducing PON2 expression, which increases ROS production and triggers Bim output that inhibits malignant progression through the cascade PON2-Bim [137]. Furthermore, valproic acid induced autophagy through the ERK1/2 pathway which led to glioma cell death. By using the combination of valproic acid and temozolomide or rapamycin, autophagy was enhanced both in vivo and in vitro [138]. Valproic acid is also studied in different drug combinations, to increase the treatment efficiency of GB [139]. Between 2018 and 2021, valproic acid is in a phase 4 clinical trial for glioma patients with their first seizure [140].

Also, the neuroprotective drug propentofylline tested for Alzheimer's disease and vascular dementia [141] was proven to target TROY, a receptor involved in the tumor necrosis factor receptor (TNFR) microglial signaling pathway [142].
Furthermore, the antimalarial agent chloroquine improved chemo-radiation treatment in GB [143], making it suitable as a re-purposing candidate [144]. Briefly, chloroquine (alone or in combination with temozolomide) leads to accumulation of autophagic vacuoles with non-functional properties, thus inhibiting autophagy $[117,145]$. Several clinical trials are currently being conducted [146].

In 2019, a phase 1 study reported unexpectedly low rates of neuropsychiatric side effects of another antimalarial agent, mefloquine, repurposed for the treatment of GB [147].

Interestingly, a possible target in GB treatment is chloride intracellular channel1 (CLIC1), known to be inhibited by the anti-diabetic biguanides [148]. Metformin is a representative of biguanides and it is the most used oral antidiabetic drug. In 2016, a set of kinases were identified as potential targets, including SGK1 and EGFR [149]. Clinical trials are currently in different stages regarding metformin in association with other drugs, in GB therapy [150].

Disulfiram is an ALDH1 inhibitor, a staminal marker for GB [151]. The activity of disulfiram increases if administered together with divalent cations (Cu gluconate). Recently, disulfiram has been reported to inhibit NF-kB [152] and methylguanine-DNA methyltransferase [153]. Eight clinical trials are currently in different stages regarding disulfiram in association with other drugs, from which 2 are completed, in GB therapy [154].

Lonidamine is a reversible inhibitor of spermatogenesis. During its clinical use in combination with other anti-cancer drugs, it exhibited promising results in brain 
Table 2. Repurposing candidates that did not receive approval for glioblastoma treatment. Although they have been considered as candidates in the re-purposing process, many old active molecules have failed to complete all steps to enter the pharmaceutical market for glioblastoma treatment, being rejected at different stages of development

\begin{tabular}{|c|c|}
\hline Class & Drugs \\
\hline Antiparasitics & $\begin{array}{l}\text { Hydroxychloroquine, quinacrine, } \\
\text { pyrvinium pamoate }\end{array}$ \\
\hline Anti-infectious & Atazanavir, ribavirin, ciprofloxacin, salinomycin, doxycycline, chloramphenicol, tigecycline \\
\hline Central nervous system & $\begin{array}{l}\text { Chlorpromazine, fluphenazine, perphenazine, olanzapine, penfluridol, quetiapine, } \\
\text { paroxetine, fluoxetine, fluvoxamine, amitriptyline, clomipramine, doxepin, propofol }\end{array}$ \\
\hline Cardiovascular system & $\begin{array}{c}\text { Digitoxin, lovastatin, simvastatin, pitavastatin, fluvastatin, evastatin, cerivastatin, } \\
\text { verapamil, carvedilol }\end{array}$ \\
\hline Blood & Ticlopidine \\
\hline Respiratory system & Ibudilast, amlexanox \\
\hline Alimentary tract and metabolism & Repaglinide, rosiglitazone, ciglitazone, phenformin, sulfasalazine, cimetidine \\
\hline Dermatologicals & Isotretinoin, ivermectin \\
\hline Genito-urinary system and sex hormones & Estradiol \\
\hline
\end{tabular}

tumors [155]. Recently, new studies show that lonidamine inhibits the lactic acid efflux mediated by the MCT proteins. In addition, lonidamine also elicits a cytotoxic autophagic response in GB cells [156].

All these agents could be re-purposed for GB treatment, but not before a better understanding of their mechanism and formulation. Also, some researchers consider that combining the drugs with re-purposing capacity may be advantageous. In 2013, the Coordinated Undermining of Survival Paths protocol (CUSP9) was developed to assess the safety of temozolomide in GB in combination with other drugs [157]. This protocol used combinations of 9 re-purposed drugs (aprepitant, minocycline, disulfiram, celecoxib, sertraline, captopril, itraconazole, ritonavir, auranofin) and low doses of temozolomide. In this monocentric trial, all patients are treated at UIm University Hospital Germany. This clinical trial is currently in phase 2. The estimated study completion date is March 2020 [158].

Despite the efforts, many drugs have failed to be approved for re-purposing in the treatment of $\mathrm{GB}[159,160]$, as can be observed in Table 2 .

\section{Conclusions}

The above described drugs are not target-specific drugs, but they can represent a therapeutic option designed rather to "target" cancer cell dependencies. Because of the heterogeneity of $\mathrm{GB}$, the re-purposing approach has great potential, since their combined administration, together with current therapeutic options, could target cancer cell survival mechanisms, thus providing a strategy to avoid drug resistance in GB treatment. The information presented herein highlights the necessity of extensive research to elucidate some of the unclear biological mechanisms that underly the therapeutic effects. This step is mandatory, in order to go through all stages of developing clinical trials, until drug marketing.

\section{Acknowledgements}

This work was supported by grant PN-III-P1-1.1-MC2019-1185

The authors declare no conflict of interest.

\section{References}

1. Louis DN, Ohgaki H, Wiestler OD, Cavenee WK, Burger PC, Jouvet A, Scheithauer BW, Kleihues P. The 2007 WHO classification of tumours of the central nervous system. Acta Neuropathol 2007; 114: 97-109.

2. Louis DN, Perry A, Reifenberger G, et al. The 2016 World Health Organization classification of tumors of the central nervous system. Acta Neuropathol 2016; 131: 803-820.

3. Huse JT, Diamond EL, Wang L, Rosenblum MK. Mixed glioma with molecular features of composite oligodendroglioma and astrocytoma: a true "oligoastrocytoma"? Acta Neuropathol 2015; 129: 151-153.

4. Wilcox P, Li CC, Lee M, et al. Oligoastrocytomas: throwing the baby out with the bathwater? Acta Neuropathol 2015; 129: 147-149.

5. Stupp R, Heigi ME, Mason WP, et al. Effects of radiotherapy with concomitant and adjuvant temozolomide versus radiotherapy alone on survival in glioblastoma in a randomized phase III study: 5-year analysis of the EORTC-NCIC trial. Lancet Oncol 2009; 10: 459-466.

6. Keles GE, Lamborn KR, Chang SM, Prados MD, Berger MS. Volume of residual disease as a predictor of outcome in adult patients with recurrent supratentorial glioblastomas multiforme who are undergoing chemotherapy. J Neurosurg 2004; 100: 41-46.

7. Stupp R, Mason WP, van den Bent MJ, et al. Radiotherapy plus concomitant and adjuvant temozolomide for glioblastoma. N Engl J Med 2005; 352: 987-96.

8. Stupp R, Hegi ME, Gilbert MR, Chakravarti A. Chemoradiotherapy in malignant glioma: standard of care and future directions. I Clin Oncol 2007; 25: 4127-4136.

9. Salvatore V, Teti G, Focaroli S, Mazzotti MC, Mazzotti A, Falconi M. The tumor microenvironment promotes cancer progression and cell migration. Oncotarget 2017; 8: 9608-9616.

10. Mizuno T, Kyoizumi S, Suzuki T, Iwamoto KS, Seyama T. Continued expression of a tissue specific activated oncogene in the early steps of radiation-induced human thyroid carcinogenesis. Oncogene 1997; 15: 1455-1460.

11. Wang M, Xie YT, Girnita L, et al. Regulatory role of mevalonate and $\mathrm{N}$-linked glycosylation in proliferation and expression of the EWS/ FLI-1 fusion protein in Ewing's sarcoma cells. Exp Cell Res 1999; 246: 38-46.

12. Shawver LK, Slamon D, Ullrich A. Smart drugs: tyrosine kinase inhibitors in cancer therapy. Cancer Cell 2002; 1: 117-123.

13. Cosaceanu D, Carapancea M, Alexandru Oana, et al. Comparison of three approaches for inhibiting insulin-like growth factor I receptor and their effects on NSCLC cell lines in vitro. Growth Factors 2007; 25: 1-8

14. Lemmon MA, Schlessinger J. Cell signaling by receptor tyrosine kinases. Cell 2010; 141: 1117-1134.

15. Blume-Jensen P, Hunter T. Oncogenic kinase signaling. Nature 2001; 411: 355-365. 
16. Ulrich A, Schlessinger J. Signal transduction by receptors with tyro sine kinase activity. Cell 1990; 61: 203-212.

17. Leppanen VM, Prota AE, Jeltsch M, et al. Structural determinants of growth factor binding and specificity by VEGF receptor 2. Proc Natl Acad Sci USA 2010; 107: 2425-2430.

18. Hubbard SR, Miller WT. Receptor tyrosine kinases: mechanisms of activation and signaling. Curr Opin Cell Biol 2007; 19: 117-123.

19. Pawson T. Specificity in signal transduction: From phosphotyrosine-SH2 domain interactions to complex cellular systems. Cell 2004; 116: 191-203.

20. Zwang Y, Yarden Y. Systems biology of growth factor - induced receptor endocytosis. Traffic 2009; 10: 349-363.

21. Critchley WR, Pellet-Many C, Ringham-Terry B, Harrison MA, Zachary IC, Ponnambalam S. Receptor tyrosine kinase ubiquitination and de-ubiquitination in signal transduction and receptor trafficking. Cells 2018; 7: 22.

22. Pearson JRD, Regad T. Targeting cellular pathways in glioblastoma multiforme. Signal Transduct Target Ther 2017; 2: 17040.

23. Popescu AM, Purcaru SO, Alexandru O, Dricu A. New perspectives in glioblastoma antiangiogenic therapy. Contemp Oncol (Pozn) 2016; 20: 109-118.

24. US Food and Drug Administration, Office of Combination Products. Annual Report to Congress: Federal Food, Drug, and Cosmet ic Act as amended by the Medical Device User Fee Act of 2002. Rockville, MD: National Press Office; October 26, 2003.

25. Kesari S, Ramakrishna N, Sauvageot C, et al. Targeted molecular therapy of malignant gliomas. Curr Neurol Neurosci Rep 2005; 5 : 186-197.

26. Ohgaki H. Genetic pathways to glioblastomas. Neuropatholology 2005; 25: 1-7.

27. Halatsch ME, Gehrke EE, Vougioukas VI, et al. Inverse correlation of epidermal growth factor receptor messenger RNA induction and suppression of anchorage-independent growth by OSI = 774, an epidermal growth factor receptor tyrosine kinase inhibitor, in glio blastoma multiforme cell lines. J Neurosurg 2004; 100: 523-533.

28. Rich JN, Reardon DA, Peery T, et al. Phase II trial of gefitinib in recurrent glioblastoma. J Clin Oncol 2004; 22: 133-142.

29. Lieberman FS, Cloughesy T, Fine $H$, et al. NABTC phase I/II trial of ZD-1839 for recurrent malignant gliomas and unresectable meningiomas. J Clin Oncol 2004; 22: 1510.

30. Franceschi E, Lonardi S, Tosoni A, et al. ZD1839 (Iressa) treatment for adult patients with progressive high-grade gliomas (HGG): an open label, single-arm, phase II study of the Gruppo Italiano Coop erativo di Neuro-Oncologia (GICNO). J Clin Oncol 2005; 23: 1564a.

31. Brown N, McBain C, Nash S, et al. Multi-center randomized phase II study comparing cediranib plus gefitinib with cediranib plus placebo in subjects with recurrent/progressive glioblastoma. PloS One 2016; 11: e0156369.

32. Vogelbaum MA, Peereboom D, Stevens G, et al. Phase II trial of the EGFR tyrosine kinase inhibitor erlotinib for single agent therapy of recurrent glioblastoma multiforme: Interim results. J Clin Oncol 2004; 22: 1558a.

33. Raizer JJ, Abrey LE, Wen P, et al. A phase II trial of erlotinib (OSI-774) in patients (pts) with recurrent malignant gliomas (MG) not on EIAEDs. J Clin Oncol 2004; 22: 1502a.

34. Peereboom DM, Ahluwalia MS, Ye X, et al. New Approaches to Brain Tumor Therapy Consortium: NABTT 0502: a phase II and pharmacokinetic study of erlotinib and sorafenib for patients with progressive or recurrent glioblastoma multiforme. Neuro-Oncol 2013; 15: 490-496.

35. Thiessen B, Stewart C, Tsao M, et al. A phase I/II trial of GW572016 (lapatinib) in recurrent glioblastoma multiforme: clinical outcomes, pharmacokinetics an molecular correlation. Cancer Chemother Pharmacol 2010; 65: 353361.

36. Karavasilis V, Kotoula V, Pentheroudakis G, et al. A phase I study of temozolomide and lapatinib combination in patients with recurrent high-grade gliomas. J Neurol 2013; 260: 1469-1480.

37. Reardon DA, Nabors LB, Mason WP, et al. BI 120036 Trial Group and the Canadian Brain Tumour Consortium: Phase I/randomized phase II study of afatinib, an irreversible ERBB family blocker, with or without protracted temozolomide in adults with recurrent glioblastoma. Neuro-Oncol 2015; 17: 430-439.
38. Sepúlveda-Sánchez JM, Vaz MÁ, Balañá C, et al. Phase II trial of dacomitinib, a pan-human EGFR tyrosine kinase inhibitor, in recurrent glioblastoma patients with EGFR amplification. Neuro Oncol 2017; 19: 1522-1531.

39. Zahonero C, Aguilera P, Ramírez-Castillejo C, et al. Preclinical Test of Dacomitinib, an Irreversible EGFR Inhibitor, Confirms Its Effectiveness for Glioblastoma. Mol Cancer Ther 2015; 14: 1548-1558.

40. Liu X, Chen X, Shi L, et al. The third-generation EGFR inhibitor AZD9291 overcomes primary resistance by continuously blocking ERK signaling in glioblastoma. J Exp Clin Cancer Res 2019; 38: 219. 41. An Z, Aksoy O, Zheng T, Fan QW, Weiss WA. Epidermal growth factor receptor and EGFRvIII in glioblastoma: signaling pathways and targeted therapies. Oncogene 2018; 37: 1561-1575.

42. Reardon DA, Conrad CA, Cloughesy T et al. Phase I study of AEE788, a novel multitarget inhibitor of ErB- and VEGFR family tyrosine kinases in recurrent glioblastoma patients. Cancer Chemother Pharmacol 2012; 69: 1507-1518.

43. Brian MA, Trippa L, Gaffey S, et al. Individualized Screening Trial of Innovative Glioblastoma Therapy (INSIGhT): A Bayesian Adaptive Platform Trial to Develop Precision Medicines for Patients With Glioblastoma. JCO Precision Oncology 2019; 3: 1-13.

44. Alexandru O, Purcaru SO, Tataranu LG, Lucan L, Castro J, Folcuţi C, Artene SA, Tuță C, Dricu A. The Influence of EGFR Inactivation on the Radiation Response in High Grade Glioma. Int J Mol Sci 2018; 19: 229.

45. Paulsson J, Ehnman M, Ostman A. PDGF receptors in tumor biology: prognostic and predictive potential. Future Oncology 2014; 10: $1695-1708$

46. Brennan CW, Verhaak RG, McKenna A, et al. The somatic genomic landscape of glioblastoma. Cell 2013; 155: 462-477.

47. De Witt H. Small molecule kinase inhibitors in glioblastoma: a systematic review of clinical studies. PCNeuro Oncol 2010; 12: 304-16.

48. Dresemann G, Weller M, Rosenthal MA, et al. Imatinib in combination with hydroxyurea versus hydroxyurea alone as oral therapy in patients with progressive pretreated glioblastoma resistant to standard dose temozolomide. J Neurooncol 2010; 96: 393-402.

49. Frolov A, Evans IM, Li N, et al. Imatinib and Nilotinib increase glioblastoma cell invasion via Abl-independent stimulation of p130Cas and FAK signalling. Sci Rep 2016; 6: 27378.

50. Batchelor TT, Gerstner ER, Ye X, et al. Feasibility, phase I, and phase II studies of tandutinib, an oral platelet-derived growth factor receptor-beta tyrosine kinase inhibitor, in patients with recurrent glioblastoma. Neuro Oncol 2016; 19: 567-575.

51. Carapancea M, Alexandru O, Fetea AS, et al. Growth factor receptors signaling in glioblastoma cells: therapeutic implications. Jeurooncol 2009; 92: 137-147.

52. Popescu AM, Alexandru O, Brindusa C, et al. Targeting the VEGF and PDGF signaling pathway in glioblastoma treatment. Int J Clin Exp Pathol 2015; 8: 7825-7837.

53. Li H, Zheng J, Guan R, Zhu Z, Yuan X. Tyrphostin AG 1296 induces glioblastoma cell apoptosis in vitro and in vivo. Oncol Lett 2015; 10: 3429-3433.

54. Alexandru O, Sevastre AS, Castro J, Artene SA, Tache DE, Purcaru OS, Sfredel V, Tataranu LG, Dricu A. Platelet-Derived Growth Factor Receptor and Ionizing Radiation in High Grade Glioma Cell Lines. Int Mol Sci 2019; 20: 4663

55. Gerstener ER, Eichler AF, Plotkin SR, et al. Phase I trial with biomarker studies of vatalanib (PTK787) in patients with newly diagnosed glioblastoma treated with enzyme inducing anti-epileptic drugs and standard radiation and temozolomide. J Neurooncol 2011; 103: 325-332

56. Lee EQ, Kuhn J, Lamborn KR, et al. Phase I/II study of sorafenib in combination with temsirolimus for recurrent glioblastoma or gliosarcoma: North America Brain Tumor Consortium study. Neuro Oncol 2012; 14: 1511-1518.

57. Kalpathy-Cramer J, Chandra V, Da X, et al. Phase II study of tivozanib an oral VEGFR inhibitor, in patients with recurrent glioblastoma. Jeurooncol 2016; 131: 603-610.

58. Reardon DA, Groves MD, Wen Py, et al. A phase I/II trial of pazopanib in combination with lapatinib in adult patients with relapsed malignant glioma. Clin Cancer Research 2013; 19: 900-908. 
59. Batchelor TT, Mulholland P, Neyns B, et al. Phase III randomized trial comparing the efficacy of cediranib as monotherapy, and in combination with lomustine, versus lomustine alone in patients with recurrent glioblastoma. J Clin Oncol 2013; 31: 3212-3218.

60. Hassler MR, Sax C, Flechl B, et al. Thalidomide as palliative treatment in patients with advanced secondary glioblastoma. Oncology 2015; 88: 173-179.

61. Batista KM, Eulate-Beramendi S, Pińa K, et al. Mesenchymal/proangiogenic factor $\mathrm{YKL}-40$ related to glioblastomas and its relationship with the subventricular zone. Folia Neuropathologica 2017; 1: $14-22$.

62. Francescone RA, Scully S, Faibish M, et al. Role of YKL-40 in the angiogenesis, radioresistance, and progression of glioblastoma. J Biol Chem 2011; 286: 15332-15343.

63. Zhou X, Zhao X, Li X, et al. PQ401, an IGF-1R inhibitor, induces apoptosis and inhibits growth, proliferation and migration of glioma cells. J Chemother 2016; 28: 44-49.

64.Zhou Q. BMS-536924, an ATP-competitive IGF-1R/IR inhibitor, decreases viability and migration of temozolomide-resistant glioma cells in vitro and suppresses tumor growth in vivo. Onco Targets Ther 2015; 8: 689-697.

65. Yin S, Girnita A, Stromberg T, et al. Targeting the insulin-like growth factor-1 receptor by picropodophyllin as a treatment option for glioblastoma. Neuro Oncol 2010; 12: 19-27.

66. Zhou X, Shen F, Ma P, et al. GSK1838705A, an IGF-1R inhibitor, inhibits glioma cell proliferation and suppresses tumor growth in vivo. Mol Med Rep 2015; 12: 5641-5646.

67. Premkumar DR, Jane EP, Pollack IF. Co-administration of NVPAEW541 and dasatinib induces mitochondrial-mediated apoptosis through Bax activation in malignant human glioma cell lines. Int J Oncol 2010; 37: 633-643.

68. Gong Y, Ma Y, Sinyuk M, et al. Insulin-mediated signaling promotes proliferation and survival of glioblastoma through Akt activation. Neuro-Oncology 2016; 18; 48-57.

69. Carapancea M, Cosaceanu D, Budiu R, et al. Dual targeting of IGF$1 R$ and PDGFR inhibits proliferation in high-grade gliomas cells and induces radiosensitivity in JNK-1 expressing cells. J Neurooncol 2007; 85: 245-254.

70. Lasorella A, Sanson M, lavarone A. FGFR-TACC gene fusions in human glioma.Neuro Oncol 2017; 19: 475-483.

71. Jimenez-Pascual A, Siebzehnrubl FA. Fibroblast Growth Factor Receptor Functions in Glioblastoma. Cells 2019; 8: 715.

72. Dieci MV, Arnedos M, Andre F, Soria JC. Fibroblast growth factor receptor inhibitors as a cancer treatment: from a biologic rationale to medical perspectives. Cancer Discov 2013; 3: 264-279.

73. Schramm K, Iskar M, Statz B, et al. DECIPHER pooled shRNA library screen identifies PP2A and FGFR signaling as potential therapeutic targets for diffuse intrinsic pontine gliomas. Neuro Oncol 2019; 21: 867-877.

74. https://clinicaltrials.gov/ct2/show/NCT02052778 Retrieved January $27^{\text {th }} 2020$.

75. https://clinicaltrials.gov/ct2/show/results/NCT01975701 Retrieved January $27^{\text {th }} 2020$.

76. Seto B. Rapamycin and mTOR: a serendipitous discovery and implications for breast cancer. Clin Transl Med 2012; 1: 29.

77. Yadavalli S, Yenugonda V, Kesari S. Repurposed Drugs in Treating Glioblastoma Multiforme: Clinical Trials Update. Cancer J 2019; 25: 139-146.

78. Kreisl TN, McNeill KA, Sul J, Iwamoto FM, Shih J, Fine HA. A phase I/ II trial of vandetanib for patients with recurrent malignant glioma. Neuro Oncol 2012; 14: 1519-1526.

79. Chheda MG, Wen PY, Hochberg FH, et al. Vandetanib plus sirolimus in adults with recurrent glioblastoma: results of a phase I and dose expansion cohort study. J Neurooncol 2015; 121: 627-634.

80. Quant EC, Batchelor T, Lassman AB, et al. Preliminary results from a multicenter, phase $I I$, randomized, noncomparative clinical trial of radiation and temozolomide with or without vandetanib in newly diagnosed glioblastoma (GB). J Clin Oncol 2011; 29: 20692069.

81. Wen PY, Prados M, Schiff D, et al. Phase II study of XL184(BMS 907351), an inhibitor of MET, VEGFR2, and RET, in patients (pts) with progressive glioblastoma (GB). J Clin Oncol 2010; 28 (15 Suppl): 2006.

82. Loilome W, Joshi AD, ap Rhys CM, et al. Glioblastoma cell growth is suppressed by disruption of Fibroblast Growth Factor pathway signaling. J Neurooncol 2009; 94: 359-366.

83. Grisanti S, Ferrari VD, Buglione M, et al. Second line treatment of recurrent glioblastoma with sunitinib: results of a phase II study and systematic review of literature. J Neurosurg Sci 2019; 63: 458-467.

84. Belda-Iniesta C, Carpeno Jde C, Saenz EC, Gutierrez M, Perona R, Baron MG. Long term responses with cetuximab therapy in glioblastoma multiforme. Cancer Biol Ther 2006; 5: 912-914.

85. Neyns B, Sadones J, Joosens E, et al. Stratified phase II trial of cetuximab in patients with recurrent high-grade glioma. Ann Oncol 2009; 20: 1596-1603.

86. Martens T, Schmidt NO, Eckerich C, et al. A novel one-armed antic-Met antibody inhibits glioblastoma growth in vivo. Clin Cancer Res 2006; 12: 6144-6152.

87. Singh P, Alex JM, Bast F. Insulin receptor (IR) and insulin-like growth factor receptor 1 (IGF-1R) signaling systems: novel treatment strategies for cancer. Med Oncol 2014; 31: 805.

88. Yap TA, Omlin A, de Bono JS. Development of therapeutic combinations targeting major cancer signaling pathways. J Clin Oncol 2013; 31: 1592-1605.

89. Sestito S, Runfola M, Tonelli M, Chiellini G, Rapposelli S. New multitarget approaches in the war against glioblastoma: a mini-perspective. Front Pharmacol 2018; 9: 874.

90. Graves-Deal R, Bogatcheva G, Rehman S, Lu Y, Higginbotham JN, Singh B. Broad-spectrum receptor tyrosine kinase inhibitors overcome de novo and acquired modes of resistance to EGFR-targeted therapies in colorectal cancer. Oncotarget 2019; 10: 1320-1333.

91. Wei W, Shin YS, Xue M, et al. Single-cell phosphoproteomics resolves adaptive signaling dynamics and informs targeted combination therapy in glioblastoma. Cancer Cell 2016; 29: 563-573.

92. Ziegler DS, Wright RD, Kesari S, et al. Resistance of human glio blastoma multiforme cells to growth factor inhibitors is overcome by blockade of inhibitor of apoptosis proteins. J Clin Investig 2008; 118: 3109-3122.

93. Gazarian M, Kelly M, McPhee JR, Graudins LV, Ward RL, Campbell TJ. Off-label use of medicines: consensus recommendations for evaluating appropriateness. Med J Aust 2006; 185; 544-548.

94. Pantziarka P, Bouche G, Meheus L, Sukhatme V, Sukhatme VP. Repurposing Drugs in Oncology (ReDO)-mebendazole as an anti-cancer agent. Ecancermedicalscience 2014; 8; 443.

95. Tan SK, Jermakowicz A, Mookhtiar AK, Nemeroff CB, Schürer SC, Ayad NG. Drug Repositioning in Glioblastoma: A Pathway Perspective. Front Pharmacol 2018; 9: 218.

96. Andresen V, Gjertsen B. Drug Repurposing for the Treatment of Acute Myeloid Leukemia. Frontiers in Medicine 2017; 4; 211.

97. Verbaanderd C, Meheus L, Huys I, Pantziarka P. Repurposing drugs in oncology: next steps. Trends Canc 2017; 3; 543-546.

98. Shorthose S, Guide to EU Pharmaceutical Regulatory Law. Bird \& Bird LLP, 2017.

99. Pantziarka P. Scientific advice - is drug repurposing missing a trick? Nat Rev Clin Oncol 2017; 14: 455-456.

100. Kurzrock R, Gurski LA, Carlson RW, et al. Level of evidence used in recommendations by the National Comprehensive Cancer Network (NCCN) guidelines beyond Food and Drug Administration approvals. Annals of Oncology 2019. pii: mdz232.

101. Vasilev A, Sofi R, Tong L, Teschemacher AG, Kasparov S. In search of a breakthrough therapy for glioblastoma multiforme. Neuroglia 2018; 1; 292-310.

102. Lefranc F, Yeaton P, Brotchi J, Kiss R. Cimetidine, an unexpected anti-tumor agent, and its potential for the treatment of glioblastoma (review). Int J Oncol 2006; 28; 1021-1030.

103. Michelakis ED, Sutendra G, Dromparis P et al. Metabolic modulation of glioblastoma with dichloroacetate. Sci Transl Med 2010; 2: $31-34$.

104.Alonso-Basanta M, Fang P, Maity A, Hahn SM, Lustig RA, Dorsey JF. A phase I study of nelfinavir concurrent with temozolomide and radiotherapy in patients with glioblastoma multiforme. J Neurooncol 2014; 116; 365-372. 
105. Pantziarka P, Sukhatme V, Bouche G, Meheus L, Sukhatme VP. Repurposing Drugs in Oncology (ReDO)-diclofenac as an anti-cancer agent. Ecancermedicalscience 2016; 10; 610.

106. Cheng HW, Liang YH, Kuo YL, et al. Identification of thioridazine, an antipsychotic drug, as an antiglioblastoma and anticancer stem cell agent using public gene expression data. Cell Death Dis 2015; 6; e1753.

107. Sukhatme V, Bouche G, Meheus L, Sukhatme VP, Pantziarka P. Repurposing Drugs in Oncology (ReDO)-nitroglycerin as an anti-cancer agent. Ecancermedicalscience 2015; 9: 568.

108. Kast RE. Glioblastoma chemotherapy adjunct via potent serotonin receptor-7 inhibition using currently marketed high-affinity antipsychotic medicines. Br J Pharmacol 2010; 161; 481-487.

109. Lee JK, Nam DH, Lee J, Repurposing antipsychotics as glioblastoma therapeutics: Potentials and challenges. Oncol Lett 2016; 11: 1281-1286.

110. Lee H, Kang S, Kim W. Drug repositioning for cancer therapy based on large-scale drug-induced transcriptional signatures. PLoS ONE 2016; 11: e0150460.

111. Krauze AV, Myrehaug SD, Chang MG, et al. A Phase 2 study of concurrent radiation therapy, temozolomide, and the histone deacetylase inhibitor valproic acid for patientswith glioblastoma. Int J Radiat Oncol Biol Phys 2015; 92: 986-992.

112. Hothi P, Martins TJ, Chen L, Deleyrolle L, Yoon JG, Reynolds B, Foltz G. High-throughput chemical screens identify disulfiram as an inhibitor of human glioblastoma stem cells. Oncotarget 2012; 3 : 1124-1136.

113. Kim YH, Kim T, Joo JD, Han JH, Kim YJ, Kim IA, Yun CH, Kim CY. Survival benefit of levetiracetam in patients treated with con comitant chemoradiotherapy and adjuvant chemotherapy with temozolomide for glioblastoma multiforme. Cancer 2015; 121 2926-2932.

114. Friesen C, Hormann I, Roscher M, Fichtner I, Alt A, Hilger R, Debatin KM, Miltner E. Opioid receptor activation triggering downregulation of CAMP improves effectiveness of anti-cancer drugs in treatment of glioblastoma. Cell Cycle 2014; 13; 1560-1570.

115. Arrieta O, Guevara P, Escobar E, García-Navarrete R, Pineda B, Sotelo J. Blockage of angiotensin II type I receptor decreases the synthesis of growth factors and induces apoptosis in C6 cultured cells and C6 rat glioma. Br J Cancer 2005; 92: 1247-1252.

116. Robe PA, Bentires-Alj M, Bonif M, et al. In vitro and in vivo activity of the nuclear factor-kappaB inhibitor sulfasalazine in human glioblastomas. Clin Cancer Res 2004; 10: 5595-5603.

117. Huang C, Hu S, Chen B. Growth inhibition of epidermal growth factor-stimulated human glioblastoma cells by nicardipine in vitro. J Neurosurg Sci 2001; 45; 151-155.

118. Assad Kahn S, Costa SL, Gholamin S, et al. The anti-hypertensive drug prazosin inhibits glioblastoma growth via the PKC-dependen inhibition of the AKT pathway. EMBO Mol Med 2016; 8; 511-526.

119. Liu WT, Huang CY, Lu IC, Gean PW. Inhibition of glioma growth by minocycline is mediated through endoplasmic reticulum stress-induced apoptosis and autophagic cell death. NeuroOncoloy 2013; 15: 1127-1141.

120. Durmaz R, Deliorman S, Uyar R, Isiksoy S, Erol K, Tel E. The effects of anticancer drugs in combination with nimodipine and verapamil on cultured cells of glioblastoma multiforme. Clin Neuro Neurosurg 1999; 101: 238-244.

121. Zhang Y, Cruickshanks N, Yuan F, et al. Targetable T-type Calcium Channels Drive Glioblastoma. Cancer Res 2017; 77: 3479-3490.

122. Weiger TM, Colombatto S, Kainz V, Heidegger W, Grillo MA, Hermann A. Potassium channel blockers quinidine and caesium halt cell proliferation in C6 glioma cells via a polyamine-dependent mechanism. Biochem Soc Trans 2007; 35: 391-395.

123. Yung WK, Kyritsis AP, Gleason MJ, Levin VA. Treatment of recurrent malignant gliomas with high-dose 13 -cis-retinoic acid. Clin Cancer Res 1996; 2: 1931-1935.

124. Toler SM, Noe D, Sharma A. Selective enhancement of cellular oxidative stress by chloroquine: Implications for the treatment of glioblastoma multiforme. Neurosurg. Focus 2006; 21: E10.

125. Baumann F, Bjeljac M, Kollias SS, Baumert BG, Brandner S, Rousson V, Yonekawa Y, Bernays RL. Combined thalidomide and te- mozolomide treatment in patients with glioblastoma multiforme. J Neurooncol 2004; 67: 191-200.

126. Rosenfeld MR, Ye X, Supko JG et al. A phase I/II trial of hydroxychloroquine in conjunction with radiation therapyand concurrent and adjuvant temozolomide in patients with newly diagnosed glioblastoma multiforme. Autophagy 2014; 10: 1359-1368.

127. Triscott J, Lee C, Hu K, et al. Disulfiram, a drug widely used to control alcoholism, suppresses the self-renewal of glioblastoma and over-rides resistance to temozolomide. Oncotarget 2012; 3: $1112-1123$

128. Lee MS, Johansen L, Zhang Y, et al. The novel combination of chlorpromazine and pentamidine exerts synergistic antiproliferative effects through dual mitotic action. Cancer Res 2007; 67: 11359-11367.

129. Shin SY, Lee KS, Choi YK, et al. The antipsychotic agent chlorpromazine induces autophagic cell death by inhibiting the Akt/ mTOR pathway in human U-87MG glioma cells. Carcinogenesis 2013; 34: 2080-2089.

130. Harder BG, Blomquist MR, Wang J, Kim AJ, Woodworth GF, Winkles JA, Loftus JC, Tran NL. Developments in blood-brain barrier penetrance and drug repurposing for improved treatment of glioblastoma. Front Oncol 2018; 8: 462.

131. Dolma S, Selvadurai HJ, Lan X, et al. Inhibition of dopamine receptor D4 impedes Autophagic flux, proliferation, and survival of glioblastoma stem cells. Cancer Cell 2016; 29: 859-873.

132. Pinheiro T, Otrocka M, Seashore-Ludlow B, Rraklli V, Holmberg J, Forsberg-Nilsson K, Simon A, Kirkham M. A chemical screen identifies trifluoperazine as an inhibitor of glioblastoma growth. Biochemical and Biophysical Research Communications 2017; 494: 477-483.

133. Johannessen TC, Hasan-Olive MM, Zhu H, et al. Thioridazine inhibits autophagy and sensitizes glioblastoma cells to temozolomide. Int J Cancer 2019; 144: 1735-1745.

134. Bielecka-Wajdman AM, Lesiak M, Ludyga T, Sieron A, ObuchowiczE. Reversing glioma malignancy: a new look at the role of antidepressant drugs as adjuvant therapy for glioblastoma multiforme. Cancer Chemother Pharmacol 2017; 79: 1249-1256.

135. Meldrum BS. Update on the mechanism of action of antiepileptic drugs. Epilepsia 1996; 37: S4-11.

136. Johannessen CU, Johannessen SI. Valproate: past, present, and future. CNS Drug Rev 2003; 9: 199-216.

137. Tseng J-H, Chen C-Y, Chen P-C, et al. Valproic acid inhibits glioblastoma multiforme cell growth via paraoxonase 2 expression. Oncotarget 2017; 8: 14666-14679.

138. Fu J, Shao CJ, Chen FR, Ng HK, Chen ZP. Autophagy induced by valproic acid is associated with oxidative stress in glioma cell lines. Neuro Oncol 2010; 12: 328-340.

139. Sachkova A, Sperling S, Mielke D, Schatlo B, Rohde V, Ninkovic M. Combined applications of repurposed drugs and their detrimental effects on glioblastoma cells. Anticancer Res 2019; 39: 207-214

140. Seizure Treatment in Glioma. ClinicalTrials.gov [Internet]. Available from: https://clinicaltrials. gov/ct2/show/NCT03048084 Retrieved December $28^{\text {th }} 2019$.

141. Rother M, Erkinjuntti T, Roessner M, Kittner B, Marcusson J, Karlsson I. Propentofylline in the treatment of Alzheimer's disease and vascular dementia: a review of phase III trials. Dement Geriatr Cogn Disord 1998; 9 (Suppl 1): 36-43.

142. Jacobs VL, Liu YN, De Leo JA. Propentofylline targets TROY, a novel microglial signaling pathway. PLoS One 2012; 7: e37955.

143. Sotelo J, Briceno E, Lopez-Gonzalez MA. Adding chloroquine to conventional treatment for glioblastoma multiforme: a randomized, double-blind, placebo-controlled trial. Ann Intern Med 2006; 144: 337-343.

144. Weyerhauser P, Kantelhardt SR, Kim EL. Re-purposing chloroquine for glioblastoma: potential merits and confounding variables. Front Oncol 2018; 8: 335.

145. Yan Y, Xu Z, Dai S, Qian L, Sun L, Gong Z. Targeting autophagy to sensitive glioma to temozolomide treatment. J Exp Clin Cancer Res 2016; 35: 23.

146. Compter I, EekersD, Hoeben A, et al. CHLOROBRAIN phase IB trial: The addition of chloroquine, an autophagy inhibitor, to concur- 
rent radiation and temozolomide for newly diagnosed glioblastoma. Annals Oncol 2019; 30 (Suppl 5): v143-v158.

147. Nevin RL. Unexpectedly low rates of neuropsychiatric adverse effects associated with mefloquine repurposed for the treatment of glioblastoma. Cancer 2019; 125: 1384-1385.

148. Barbieri F, Würth R, Pattarozzi A, et al. Inhibition of Chloride In tracellular Channel 1 (CLIC1) as Biguanide Class-Effect to Impai Human Glioblastoma Stem Cell Viability. Front Pharmacol 2018; 9: 899 .

149. Hart T, Dider S, Han W, Xu H, Zhao Z, Xie L. Toward repurposing metformin as a precision anti-cancer therapy using structura systems pharmacology. Sci Rep 2016; 6: 20441

150. Bioavailability of Disulfiram and Metformin in Glioblastomas (INSIDE) https://clinicaltrials.gov/ct2/show/NCT03151772, Retrieved December 28 2019.

151. Rasper M, Schafer A, Piontek G, et al. Aldehyde dehydrogenase 1 positive glioblastoma cells show brain tumor stem cell capacity. Neuro-Oncology 2010; 12: 1024-1033.

152. Liu P, Brown S, Goktug T, et al. Cytotoxic effect of disulfiram/copper on human glioblastoma cell lines and ALDH-positive cancerstem-like cells. Br J Cancer 2012; 107: 1488-1497.

153. Paranjpe A, Zhang R, Ali-Osman F, Bobustuc GC, Srivenugopal KS. Disulfiram is a direct and potent inhibitor of human 06-meth ylguanine-DNA methyltransferase (MGMT) in brain tumor cells and mouse brain and markedly increases the alkylating DNA damage. Carcinogenesis 2014; 35: 692-702.

154. https://clinicaltrials.gov/ct2/results?cond=Glioblastoma\&ter$m=$ disulfiram \&cntry $=\&$ state $=\&$ city $=\&$ dist $=$ (access: December $28^{\text {th }}$ 2019).

155. Carapella CM, Paggi MG, Calvosa F, et al. Lonidamine in the combined treatment of malignant gliomas. A randomized study. J Neurosurg Sci 1990; 34: 261-264

156. Davidescu M, Macchioni L, Scaramozzino G, et al. The energy blockers bromopyruvate and lonidamine lead GL15 glioblastoma cells to death by different p53-dependent routes. Sci Rep 2015; 5: 14343 .

157. https://clinicaltrials.gov/ct2/results?term $=$ Temsirolimus\&cond=glioblastoma\&Search $=$ Apply\&recrs $=$ a\&age_v $=\& g n d r=\&$ type $=\&$ rslt $=$ Retrieved December $28^{\text {th }} 2019$

158. Kast RE, Boockvar JA, Brüning A, et al. A conceptually new treatment approach for relapsed glioblastoma: Coordinated undermining of survival paths with nine repurposed drugs (CUSP9) by the International Initiative for Accelerated Improvement of Glioblastoma Care. Oncotarget 2013; 4: 502-530.

159. https://clinicaltrials.gov/ct2/show/NCT02770378?term=CUSP9\&draw $=2 \&$ rank $=1$ Retrieved January $3^{\text {rd }} 2020$.

160.Abbruzzese C, Matteoni S, Signore M, Cardone L, Nath K, Glickson JD, Paggi MG. Drug repurposing for the treatment of glioblastoma multiforme. J Exp Clin Cancer Res 2017; 36: 169.

\section{Address for correspondence}

\section{Anica Dricu}

Unit of Biochemistry

University of Medicine and Pharmacy of Craiova

2-4 Petru Rareş St.

200349 Craiova, Romania

e-mail: anica.dricu@live.co.uk

Submitted: 7.01.2020

Accepted: 24.02.2020 